relationship with 1 or 4 , since I know nothing of the detail of their investigation. The drawings, I feel, do not help sufficiently in making a critical clinical comparison.

There is an aetiological factor in connection with Case 1 which had to be considered at the beginning, viz., a self-inflicted injury. There were features present when the patient was first seen which strongly suggested the effects of an irritant on the conjunctiva. There was also a definite history of a cinder burn. In those localities where the effects of irritants on the conjunctivae are an every-day occurrence, it is not uncommon to see lesions closely resembling the condition of Case 1 in its early stages. It was thought, however, that the eye did not behave like a straight-forward burn lesion. It seemed therefore desirable to eliminate a self-inflicted injury by tarsorrhaphy and security bandages, with observation in a detention -ward. The resulting evidence was against a self-inflicted injury, but not against the necrotic ulceration having resulted from an irritant. That the process should have continued so long with recurring foci of necrosis is unlike the course of the average conjunctival lesion due to an irritant, and suggests that some chronic infective granulomatous process played at least a secondary part.

-Yours truly,

ROBERT E. WRIGHT.

AĹDERSHOT,

November 20, 1942.

\title{
SURGICAL DIATHERMY IN CHOROIDAL MELANOMA
}

To the Editors of THE BRITISH JOURNAL OF OPHTHALMOLOGY.

DEAR SiRS, - I was much interested in Messrs. Savin and Pritchard's:article on "A Choroidal Melanoma treated by Surgical Diathermy;" in the December number of the Journal. It illustrates admirably the value of this form of attack for the destruction of certain neoplasms within the eye, and I think its value for some other localised fundus conditions might well repay investigations. I have in mind more especially, localised retinal angiomata and the affected vessels in Eales' Disease ; without having tried it I suggested that it might prove of value in small retinal gliomata (Trans. Ophthal. Soc. U.K., 1935, Vol. LV, p. 19). My present object, however, is to express doubt as to whether Messrs. Savin and Pritchard's case is properly described as a melanoma of the choroid.

A good many years ago I published in The Moorfields Reports (I regret I have not the precise reference by me) what I believe was the first instance in which a melanoma of the choroid, having been examined during life, was afterwards obtained for pathological examination owing to the death of the patient, from myasthenia 
gravis: de Schweinitz and Shumway had previously reported a case, but it had not been examined ophthalmoscopically.

In the above paper micro-photographs of both bleached and unbleached sections of the tumours are reproduced; there is also included a coloured drawing by Hamblin of the same condition in another patient, and this one might describe as having the typical appearance. At a later date I obtained another specimen for pathological examination owing to the death of the patient from a cerebral tumour, which case also I had examined a number of times during life; it was published with micro-photographs in the Brit. Jl. of Ophthal., I think in the first number.

These tumours are not very rare but if small and thin may rather easily be overlooked. The largest I have seen was about three times the size of the optic disc. They are innocent growths; I have traced a number of them for a period of years; the longest of which I can be sure is the one referred to above of which the coloured drawing is, included in The Moorfields Reports; nine years later it was quite -unaltered in appearance. Whether they mayoccasionally become malignant I cannot of course say, I should expect they might, bu I should have no doubt that this seldom occurs; I have not seen it happen.

The ophthalmoscopic appearance of these tumours is quite characteristic; of the two most important features I should give first place to the colour, it is a homogeneous slate grey, exactly that of unguentum hydrarg (blue ointment). Secondly, the edges, which for want of a better term, I should describe as feathered. The tumours are more or less circular in outline; are mostly in the central region; if of any size their prominence can be made out and the retinal vessels passing over them are darkened in colour owing to the dark background.

Judging from Hamblin's drawing of Messrs. Savin and Pritchard's case, I think one may safely say that this tumour was of much too dense and much too dark a colour for a choroidal melanoma, and that its edges were altogether too even and sharp cut for this condition.

My impression is, that but for Mr. Savin's observation that at the end of three weeks " the growth was extending slightly," which is of course conclusive of its aggressive nature, one might have taken it for a congenital patch in the pigment epithelium.

I feel that the Authors are to be congratulated upon their line of treatment and upon their success; it would seem clear, as they suggest, that even if one assumed that the headaches were due to metastases, nothing would have been gained by enucleation, and that their treatment has so completely destroyed the growth that future metastases are guarded against as effectively as if the eye had been removed.

Yours truly,

December 10, 1942.

R. Foster MOORE. 